\title{
O uso racional do diurético de alça
}

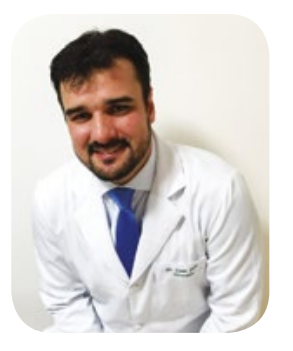

\section{INTRODUÇÃO}

Os diuréticos são uma classe essencial e heterogênea de agentes comumente usados no tratamento da hipertensão, insuficiência cardíaca e distúrbios eletrolíticos. Dentre eles estão os diuréticos de alça, sendo seu maior representante a furosemida.

Descoberta em 1964 e com farmacocinética conhecida desde 1983, a furosemida alcançou a prática diária da maior parte das especialidades clínicas. Mesmo assim, continua sendo uma droga com constantes falhas em sua prescrição. Diante desse cenário, esta revisão se presta a fazer uma atualização do emprego racional dos diuréticos de alça, corrigindo falhas e vícios da nossa prática diária.

\section{MECANISMO DE AÇÃO E FARMACOCINÉTICA}

A furosemida liga-se e bloqueia diretamente o cotransportador $\mathrm{Na}+/ \mathrm{K}+/ 2 \mathrm{Cl}$ - na porção espessa da alça ascendente dos néfrons (1) (Figura 1). No entanto, muitos passos influenciam a sua chegada até seu sítio primário de ação e, por conseguinte, podem inviabilizar a sua adequada ação. Desta forma, torna-se imprescindível o adequado conhecimento da farmacocinética e farmacodinâmica da droga.
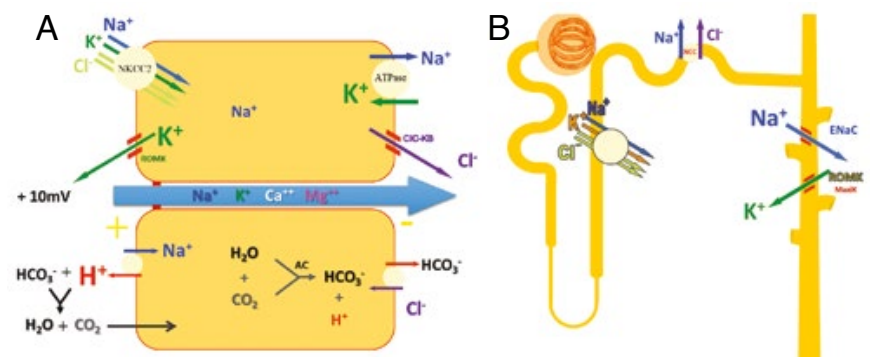

Figura 1 - A - Mecanismos de ação do diurético de alça. A figura mostra um modelo de células da porção espessa da alça de Henle. $\mathrm{Na}+\mathrm{e} \mathrm{Cl}$ - são reabsorvidos através da membrana apical através do cotransportador
$\mathrm{Na}+-\mathrm{K}+-2 \mathrm{Cl}-$ (NKCC2). Os diuréticos de alça ligam-se e bloqueiam diretamente essa via. Pode-se perceber que a tensão transepitelial ao longo da porção espessa da alça de Henle é orientada compositiva em relação ao sangue ( $10 \mathrm{mV}$ - oriunda do retorno de $\mathrm{K}+$ pelos receptores ROMK, para o lúmen tubular), gerando gradiente elétrico para transporte paracelular dos cátions $(\mathrm{Na}, \mathrm{K}$, $\mathrm{Ca}, \mathrm{Mg}$ ). B - Relação entre a porção ascendente da alça espessa, do túbulo contorcido distal e coletor. Crucial para o entendimento dos mecanismos de adaptação (descritos no texto).

Portanto, para facilitar o entendimento, siga passo por passo:

$1^{\circ}$ passo - O primeiro conceito imprescindível para prática clínica é a biodisponibilidade oral dos diuréticos de alça em indivíduos saudáveis, com impressionante variação entre 11 e $90 \%$ (Tabela 1). Ou seja, apesar de não haver nenhum mecanismo de adaptação ou resistência, indivíduos normais poderão necessitar de doses orais maiores de furosemida para uma mesma ação diurética(2). Portanto, considerando que em um indivíduo sadio a dose efetiva é de $20 \mathrm{mg}$ por dose (para maior parte da população sadia), a dose de furosemida poderá variar de 22,2mg a 181,8mg.

Tabela 1. Biodisponibilidade dos diuréticos. Adaptado de: Brater DC. Diuretic therapy. N Engl J Med 339: 387395, 1998 e Ellison DH. Diuretic therapy and resistance in congestive heart failure.Cardiology $2001 ; 96: 132-43^{5,6}$.

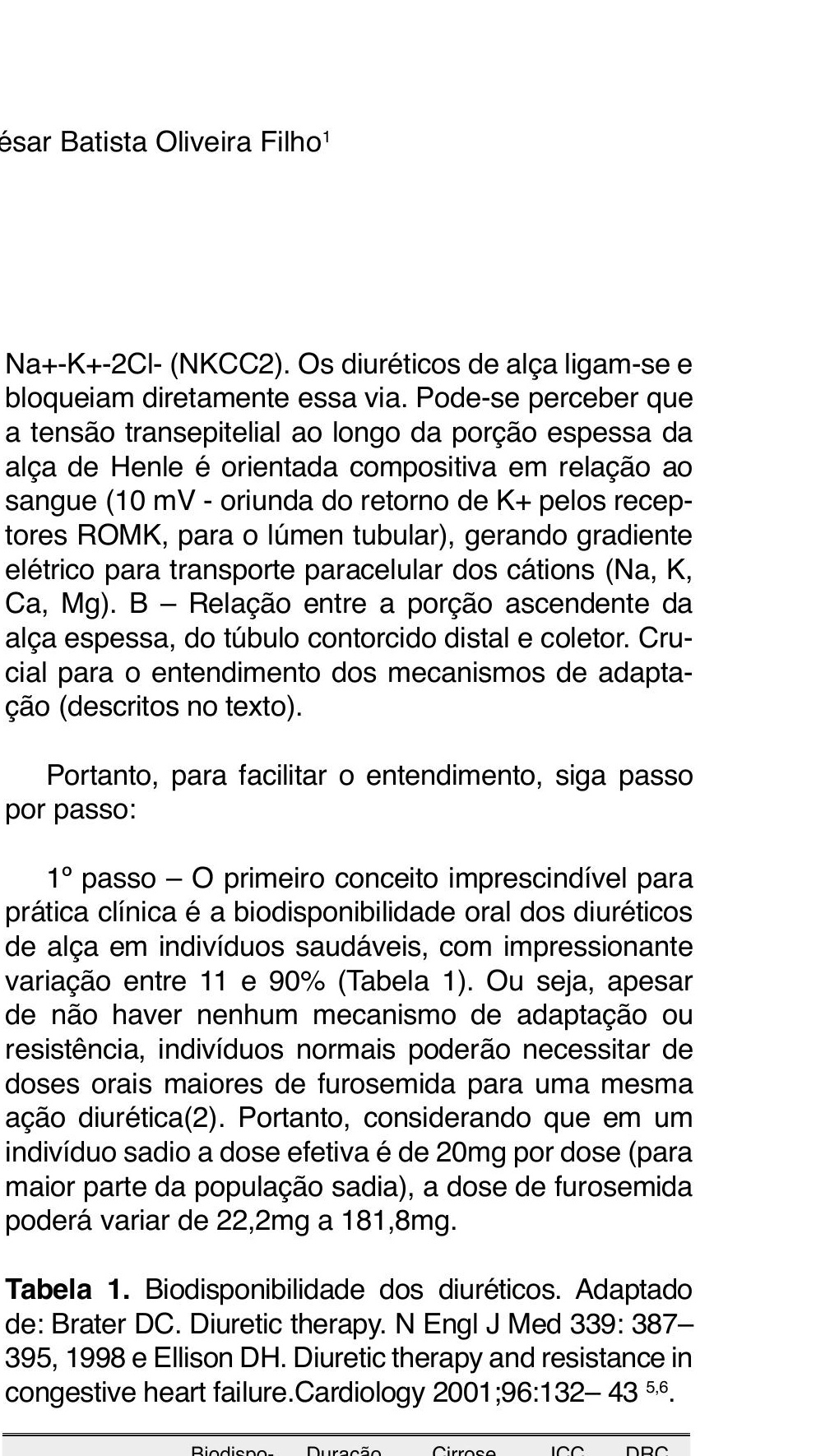




\begin{tabular}{lccccc}
\hline \hline Indapamida & 93 & $15-25$ & ND & ND & ND \\
Amilorida & ND & $17-26$ & 100 & ND & ND \\
\hline \hline Espironolactona & ND & 1.5 & ND & ND & ND
\end{tabular}

$2^{\circ}$ passo - Em situações de edema, considerando a administração via oral, a absorção da furosemida na mucosa intestinal tornar-se-á mais lenta, porém sem alterar a dose total absorvida (4). Com isso, como veremos abaixo no conceito de "dose efetiva", pelo curto tempo de meia-vida da droga (alta depuração), o alvo de concentração tubular luminal pode ser prejudicado, podendo tornar a dose utilizada ineficaz para induzir natriurese (Figura 2 - exemplifica o impacto de diurético em um paciente descompensado e edemaciado e depois em seu peso seco).

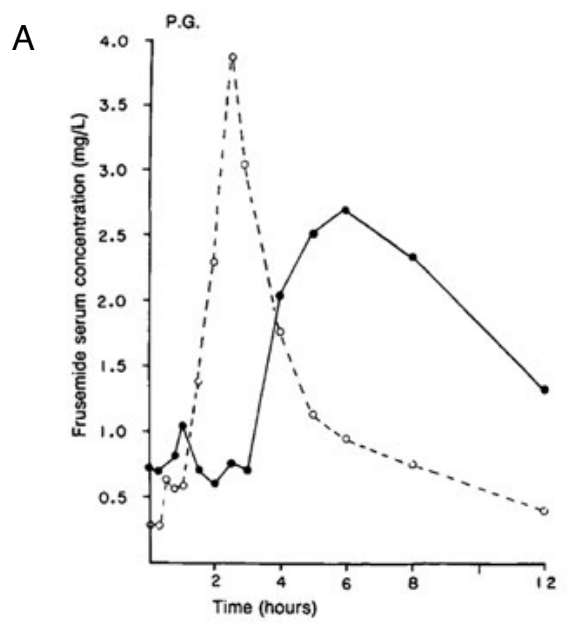

B

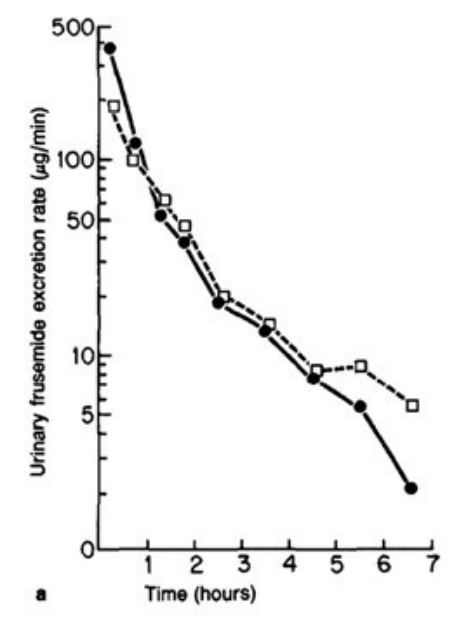

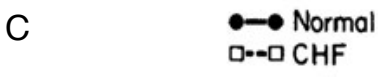

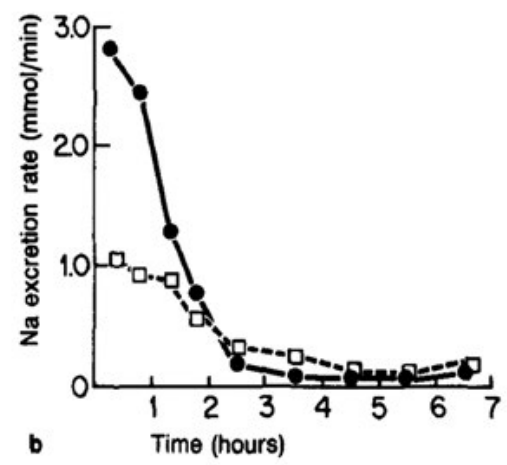

Figura 2 - A - Curso de tempo representativo da concentração sérica de furosemida em pacientes com insuficiência cardíaca congestiva após administração oral de $160 \mathrm{mg}$, quando no estado descompensado furosemida $(\bullet-\bullet)$ e após sua ( $\square-\square)$ compensação, portanto mais lenta e com menor pico de concentração. B e $\mathrm{C}$ - excreção urinária de furosemida e sódio em dois pacientes com insuficiência cardíaca enquanto descompensados $(\square-\square)$ e após atingir seu peso seco $(\bullet-\bullet)$. Ou seja, absorção lenta, menor pico sérico e taxa de excreção renal constante resultarão em baixa concentração intratubular de furosemida e risco de resistência ao uso da droga.Adaptado de: Brater, D. Craig. "Resistance to loop diuretics. Why it happens and what to do about it." Drugs 30.5 (1985): 427-443.(4)

Aplicação prática 1. Em uma situação hipotética, um indivíduo com insuficiência cardíaca compensada absorve em $50 \%$ dos $40 \mathrm{mg}$ de furosemida oral, iniciando a resposta diurética cerca de 30 minutos após administração da droga, quando os $20 \mathrm{mg}$ absorvidos chegarão "juntos" aos cotransportadores $\mathrm{Na}+/ \mathrm{K}+/ 2 \mathrm{Cl}$, saturando-os e induzindo natriurese, perpetuando o seu efeito por cerca de 2h30min. Em situações de descompensação, o edema de mucosa intestinal fará uma absorção mais lenta dos $20 \mathrm{mg}$ de furosemida durante todo o TGI (trato gastrointestinal). Portanto, hipoteticamente, com $30 \mathrm{mi}-$ nutos teremos $12 \mathrm{mg}$ de furosemida na porção espessa da alça de Henle, não sendo capaz de saturar todos os receptores $\mathrm{Na}+/ \mathrm{K}+/ 2 \mathrm{Cl}$. Desta maneira, quando os $8 \mathrm{mg}$ restantes atingirem o túbulo, diante da rápida depuração, parte dos $12 \mathrm{mg}$ que já estavam na alça de Henle já foi eliminado, não atingindo os $20 \mathrm{mg}$ necessários para saturar todos dos receptores $\mathrm{Na}+/ \mathrm{K}+/ 2 \mathrm{Cl}$ e induzir 
natriurese, tornando a dose ineficaz. Ou seja, apesar da mesma dose total ter sido absorvida (20mg), no paciente edemaciado a dose pode ser incapaz de atingir a dose efetiva (vide conceito abaixo).

A maneira mais simples de superar esse obstáculo seria aumentando a dose oral de furosemida (biodisponibilidade oral média de cerca de 50\%) e/ou modificando a via de administração para parenteral (biodisponibilidade de 100\%) - algo muito útil em pacientes com quadros agudizados. Apesar disso, não importa a via de administração (oral ou venosa, jejum ou pós-prandial) ${ }^{5}$, a natriurese da droga é a mesma, desde que alcance a concentração luminal adequada, ou seja, a dose efeti$v^{5,6}$, mudando apenas o tempo até o início da ação e a duração da natriurese.
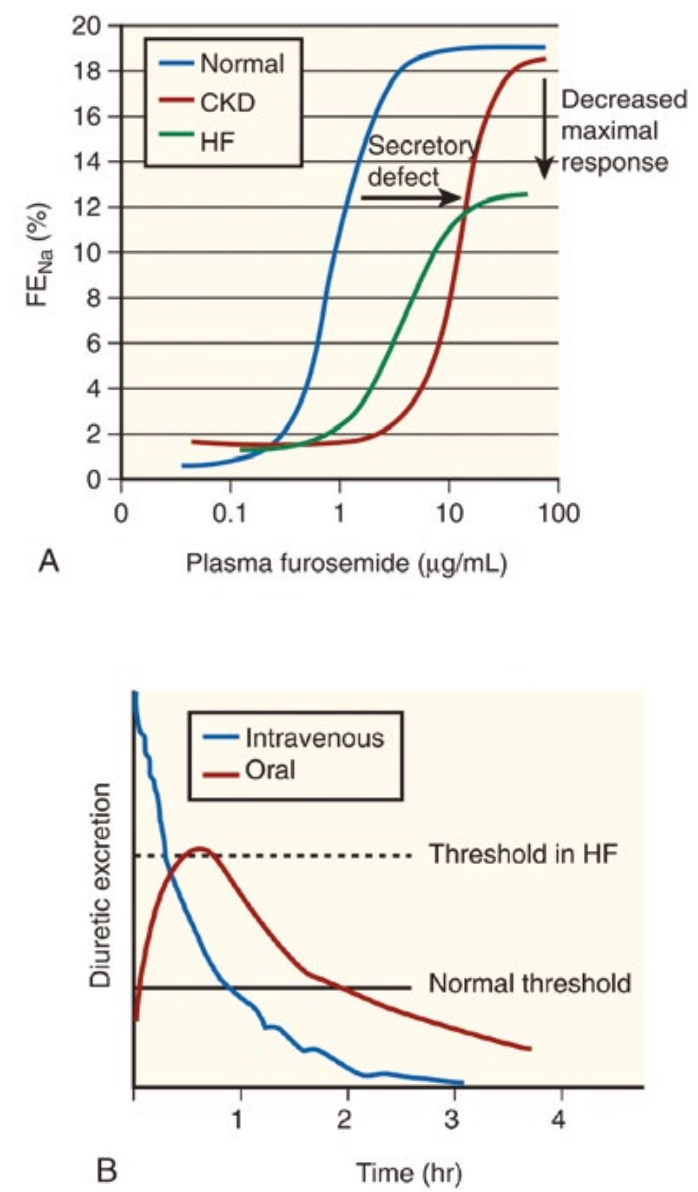

Figura 3 - Curvas de dose-resposta para diuréticos de alça. A - Fração de excreção de sódio (FENa) como função da concentração de diuréticos de alça. Em compa- ração com pacientes normais, pacientes com insuficiência renal crônica (CRF) mostram uma mudança para a direita na curva, devido à secreção diurética alterada. Resposta máxima é preservada quando expressa como FENa, mas não quando expressa como excreção absoluta de $\mathrm{Na}$. Os pacientes com insuficiência cardíaca congestiva (CHF) demonstram um deslocamento para a direita e para baixo, mesmo quando a resposta é expressa como FENa e, portanto, é relativamente resistente a diuréticos. B- Comparação da resposta a doses intravenosas e orais de diuréticos de alça. Em um indivíduo normal (Normal), a dose oral pode ser tão efetiva como uma dose intravenosa, porque o tempo acima do limiar natriurético (indicado pela linha "Normal") é aproximadamente igual. Se o limiar natriurético aumenta [como indicado pela linha cinza, de um paciente com insuficiência cardíaca congestiva (CHF)], a dose oral pode não fornecer um nível sérico suficiente para provocar natriurese. Adaptado de: Ellison, David H. "Diuretic therapy and resistance in congestive heart failure." Cardiology 96.3-4 (2001): 132-143(7).

$3^{\circ}$ passo - A furosemida, após ser absorvida, não permanece em sua forma livre, e sim com cerca de $95 \%$, formando uma ligação estável com a albumina. Portanto, a albumina é imprescindível para a circulação da molécula de furosemida pelo corpo e consequentemente para chegar a seu órgão-alvo - sendo esta prejudicada em situações de hipoalbuminemia (8). Fatores adicionais ao processo são a micro e macrocirculação renal, que precisam estar íntegras para uma adequada penetração da droga.

Aplicação prática 2 - Diante do exposto, situações de hipoalbuminemia e hipoperfusão (ativação do SRAA e sistema nervoso simpático) podem exigir utilização de uma maior dose para se obter o efeito desejado, ou até mesmo inviabilizar natriurese satisfatória.

$4^{\circ}$ passo - Ao chegar no parênquima renal, a furosemida está ligada à albumina, que, em situações de normalidade, não passa pela barreira de filtração glomerular e, por conseguinte, não será filtrada pelo glomérulo. Com isso, a furosemida precisará ser secretada no túbulo contorcido proximal (TCP) - com consumo de ATP - para conseguir atingir o lúmen tubular (Figura 4). Este mecanismo ocorre no segmento $\mathrm{S} 2$ do túbulo proximal, através de um transportador de ácidos orgânicos ( $50 \%$ secretada de forma inalterada e os outros $50 \%$ conjugado com o ácido glicurônico) ${ }^{2}$. 


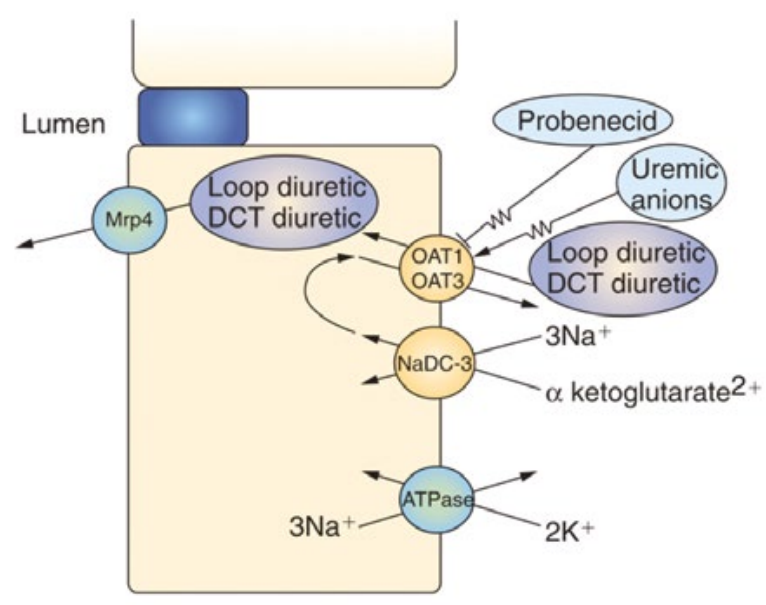

Figura 4 - Mecanismos de secreção diurética pelo TCP. Diagrama celular do segmento S2 do túbulo proximal, mostrando secreção de diuréticos aniónico, incluindo diuréticos de alça e tiazídico (ou túbulo contorcido distal - DCT). Captação peritubular por um transportador anião orgânico (principalmente OAT1, embora OAT3 possa tornar a ter um papel menor) ocorre em troca de a-cetoglutarato, que é introduzido na célula pelo transportador dependente de cátions de $\mathrm{Na}+\mathrm{NaDC}-3$. A secreção luminal pode ocorrer através de uma via dependente da tensão ou em troca de hidroxilo luminal $(\mathrm{OH}-)$ ou urato. Na porção do luminal, o transporte ocorrerá por receptor relacionado à proteína 4 (Mrp4) - relacionada à resistência a múltiplos medicamentos. ATPase, adenosina trifosfato ${ }^{9}$.

Aplicação prática 3 - Em situações como doença renal crônica, tanto o acúmulo de ácidos (competem pelo OAT) como a baixa reserva de ATP e alteração parenquimatosa poderão contribuir para o mecanismo de resistência à droga.

$5^{\circ}$ passo - Agora que atingiu livre o lúmen tubular (Figura $5 \mathrm{~A}$ ), a molécula de furosemida segue o fluxo urinário até sua ligação direta, na porção intraluminal, com a bomba $\mathrm{Na}+/ \mathrm{K}+/ 2 \mathrm{Cl}$ - (Figura $5 \mathrm{~B}$ ), presente na porção espessa da alça de Henle (Figura $5 \mathrm{C}$ ). Desta maneira, ao atingir a concentração necessária para "saturar" todos os receptores da bomba $\mathrm{Na}+/ \mathrm{K}+/ 2 \mathrm{Cl}-$, a dose efetiva é atingida e, por conseguinte, é desencadeada a natriurese desejada (Figura 7D) ${ }^{2}$.

Clinicamente, a dose efetiva pode ser presumida por dados indiretos: redução do peso diário em jejum, aumento do débito urinário total e, principalmente o au- mento do débito urinário 30 minutos a 02 (duas) horas após o uso de diurético de alça intravenoso. Nessas condições, provavelmente atingimos a dose efetiva para aquele momento clínico - afinal, pode variar de acordo com outros fatores com albumina sérica, ingesta de sódio no período interdiurético, disfunção renal e outras.
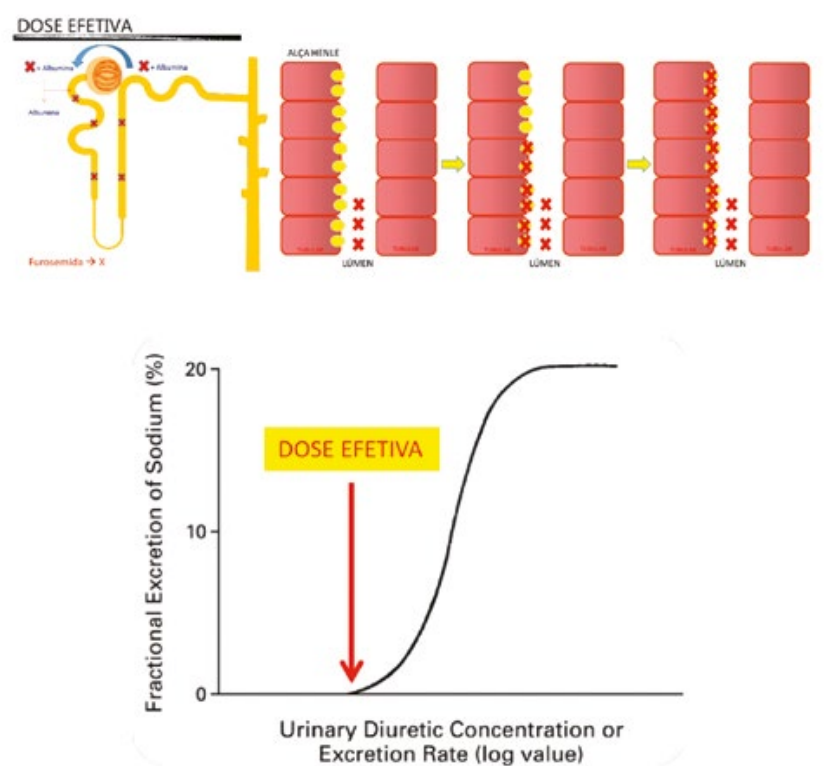

Figura 5 - Diurético de alça e dose efetiva.

Aplicação prática 4 - Como a furosemida só inibe diretamente a bomba $\mathrm{Na}+/ \mathrm{K}+/ 2 \mathrm{Cl}$ - em sua forma livre, não conjugada com a albumina, situações como proteinúria, em que a albumina chegará ao lúmen tubular, a furosemida terá uma ligação estável com a mesma, e então serão necessárias maiores doses para garantir sua dose efetiva. Esse é um dos mecanismos de resistência ao diurético das doenças proteinúricas como DM2.

Apesar de ter ação em sítio diferente, alguns diuréticos tiazídicos possuem o mesmo racional de secreção tubular (Ex.: clortalidona e hidroclorotiazida), sendo este um importante mecanismo de resistência natural a estas drogas ${ }^{2}$.

$6^{\circ}$ passo - Diversas características farmacodinâmicas dos diuréticos são clinicamente importantes. Existe uma quantidade mínima de droga que deve ser alcançada no seu local de ação, para que se possa obter uma resposta (dose efetiva). O diurético deve, portanto, ser titulado em cada paciente, a fim de determinar a dose suficiente a ser fornecida para alcançar 
a parte íngreme da curva mostrada na Figura 5. Além disso, pode-se determinar a menor dose que suscita uma resposta máxima e isso não deve ser excedido, o que, em indivíduos normais, é cerca de $40 \mathrm{mg}$ de furosemida intravenosa ou uma dose equivalente de outros diuréticos de alça- resultando excreção de 200 a $250 \mathrm{mmol}$ de sódio em 3 a 4 litros de urina durante um período de três a quatro horas ${ }^{2,10}$.

Aplicação prática 5 -Após descobrir a dose efetiva de seu paciente, o próximo passo será determinar a frequência necessária para atingir o desfecho clínico desejado (natriurese e redução do peso corporal total). Por exemplo, em um paciente com restrição de sódio e uso de furosemida $40 \mathrm{mg}$ após almoço (comprovadamente efetiva para o mesmo), que tem ganho ponderal de 500mg e piora progressiva dos níveis pressóricos, o ideal não será aumentar a dose para $80 \mathrm{mg}$ por dia, e sim passar o uso para 40mg duas vezes por dia - monitorando resposta por diurese e, principalmente, peso diário em jejum. Ou seja, aumentar a dose incrementará pouco na natriurese, sendo importante o aumento ou redução da frequência.

$7^{\circ}$ passo - A maioria dos diuréticos de alça, com exceção da torsemida, são drogas de ação curta (Tabela 1), mantendo apenas por um curto período de tempo a alta concentração tubular necessária para natriurese desejada. Portanto, após este tempo, a concentração de diurético no plasma e no líquido tubular cai a valores abaixo do limiar diurético e a reabsorção renal de sódio não é mais inibida, resultando em um período de antinatriurese ou retenção de $\mathrm{NaCl}$ pós-diurético (Figura 8). Desta maneira, tornar-se-á imprescindível uma adequada restrição de sódio e ajuste da frequência do uso do diurético de alça para o efeito desejado: natriurese e controle ponderal.

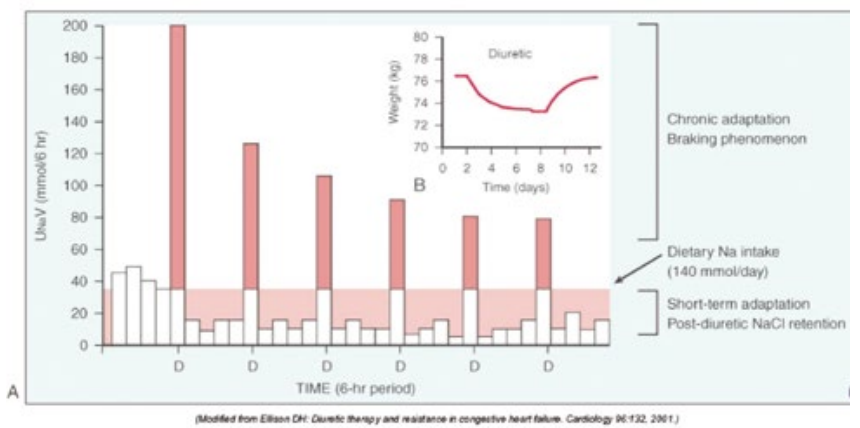

Figura 6 - Efeitos de diuréticos na excreção urinária de $\mathrm{Na}$ e volume de fluido extracelular. Inserção: efeito de um diurético sobre o peso corporal, tomado como índice de volume ECF. Observe que o estado estacionário é alcançado dentro de 6-8 dias, apesar da administração diurética contínua. Gráfico principal: efeitos de um diurético de alça na excreção urinária de $\mathrm{Na}$ (UNaV). As barras representam períodos de 6 horas antes (no saldo de $\mathrm{Na}$ ) e após doses de diurético de alça (D). A linha pontilhada indica a ingestão dietética de $\mathrm{Na}$. A porção sólida das barras indica a quantidade pela qual a excreção de $\mathrm{Na}$ excede a ingestão durante a natriurese. As áreas hachuradas indicam a quantidade de saldo $\mathrm{Na}$ positivo após o efeito diurético ter desgastado. O saldo de Na durante $24 \mathrm{~h}$ é a diferença entre a área hachurada (retenção pós-diurética de $\mathrm{NaCl}$ ) e a área sólida (natriurese induzida por diuréticos). A adaptação crônica é indicada por efeitos natriuréticos de pico progressivamente menores (o fenômeno de travagem) e é refletida por um equilíbrio de retorno ao neutro, conforme indicado na inserção, onde as áreas sólidas e produzidas são iguais... Adaptado de: Ellison, David H. "Diuretic therapy and resistance in congestive heart failure." Cardiology 96.3-4 (2001): 132-1437.

Aplicação prática 6 - Portanto, restrição de sódio é imprescindível para uma resposta clínica adequada ao diurético de alça - acarretando em um balanço negativo de sódio e redução do peso corporal total.

Esse "efeito rebote" na volemia em pacientes em uso de diurético é ainda mais pronunciado se a ingestão dietética de $\mathrm{NaCl}$ for de moderada a excessiva, causando uma maior retenção de $\mathrm{NaCl}$ e água com ativação do neuro-hormonal. Nesta situação, a retenção de $\mathrm{NaCl}$ pós-diurético pode sobrepujar a natriurese inicial e, mesmo com diureticoterapia eficaz, o paciente poderá ganhar peso. Esta observação forma a base para a administração de diuréticos de curta duração várias vezes ao dia para obter perdas diárias de sal e água consistentes (Figura 6) ${ }^{7}$.

$8^{\circ}$ Passo - O mecanismo de tolerância aguda/imediata à furosemida é creditado a uma ativação neuro-hormonal, desencadeado pela hipovolemia relativa durante o período de natriurese (5). Já o mecanismo crônico é gerado pela hipertrofia dos túbulos distal e coletor, que irão compensar parcialmente a excreção de sódio imposta pelo bloqueio da bomba $\mathrm{Na}+/ \mathrm{K}+/ 2 \mathrm{Cl}$ - evento que se inicia nos seis a oito primeiros dias de uso da furosemida. Este é um dos racionais para a utilização prática da associação de diuréticos ${ }^{11-13}$. 
Aplicação prática 7 - Comorbidades associadas à ativação do SRAA e sistema nervoso simpático (eixo neuro-hormonal) como insuficiência cardíaca, hepática e congestão venosa renal irão exigir doses progressivamente maiores de diurético para alcançar um mesmo efeito durante a progressão de sua doença ("dose efetiva") e também maior frequência - pela importante reabsorção de sódio nos períodos entre as doses do diurético. Portanto, a dose da furosemida é um marcador de gravidade da doença, inferindo importante ativação neuro-hormonal ${ }^{14 ; 15}$.

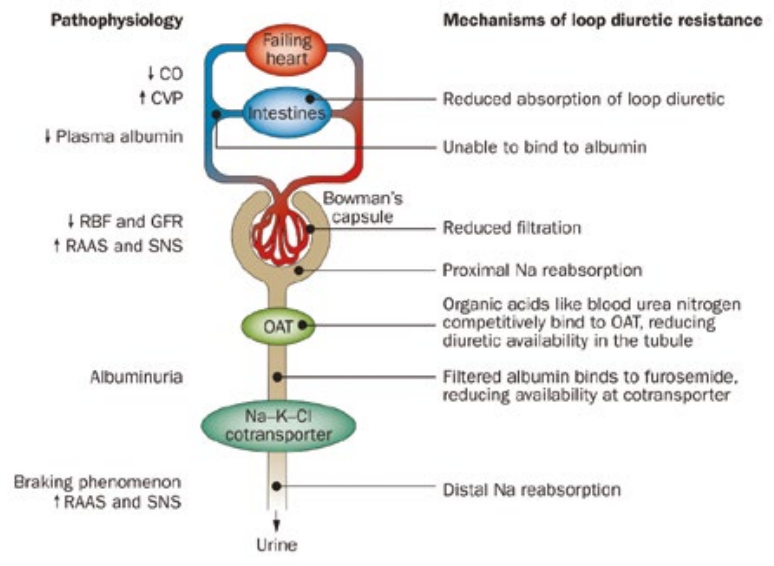

Figura 7 - Mecanismos de resistência ao diurético de alça. Os pacientes que são resistentes ao diurético de alça podem ter reduzido a absorção do fármaco no intestino, filtração reduzida ou aumentada reabsorção de sódio túbulo proximal, ou ainda por redução da disponibilidade das drogas no túbulo. Abreviações: $\mathrm{CO}$, cardiac output; CVP, central venous pressure; GFR, glomerular filtration rate; OAT, organic anion transporter; RAAS, renin-angiotensin-aldosterone system; RBF, renal blood flow; SNS, sympathetic nervous system. Adaptado de: Ter Maaten, J. M. et al. Nat. Rev. Cardiol. advance online publication 6 January $2015^{16}\left(^{*}\right) \mathrm{Na}$ realidade, não há uma redução da absorção intestinal do diurético, e sim uma lentificação desse processo. Com isso, como a excreção renal começa a ocorrer, o fármaco pode não atingir o limiar diurético no lúmen do túbulo renal. (ver FIGURA 2 e 3).

Aplicação prática 8 - Pacientes em uso crônico de diurético de alça, ao fazer uma suspensão abrupta da droga, terão redução dramática do fluxo urinário. Esse comportamento é esperado e pode ser atribuído à presença de hipertrofia dos túbulos contorcidos distal e coletor, estimulada pelo uso crônico de furosemida (haverá um "down regulation" com o passar dos dias sem uso do diurético). Com isso, principalmente em unidades de terapia intensiva, quando for necessário suspensão do diurético, tenha redobrada atenção ao utilizar o débito urinário como marcador de lesão renal aguda.

\section{$9^{\circ}$ Passo - ASSOCIAÇÃO DE DIURÉTICOS}

Como descrito acima, o mecanismo de adaptação crônico ao uso de diurético de alça é desconhecido, mas credita-se à secundária hipertrofia dos túbulos contorcidos distal e coletor. Portanto, a terapia combinada com duas classes de fármacos pode melhorar a eficácia do diurético de alça ${ }^{17}$ e estudos clínicos tendem a confirmar essa impressão. No entanto, apesar do racional de "associação", a maioria dos estudos publicados determinaram doses arbitrárias e fixas do diurético de alça, sem "dose efetiva" individualizada e, portanto, susceptíveis a desfecho clínico favorável ao uso de associação. Desse modo, as duas opções parecem ser viáveis: aumentar a dose do diurético de alça até atingir a dose efetiva e, a partir daí, alcançar a frequência adequada; ou associar diuréticos. Deve-se atentar apenas para risco de hipocalemia na associação de diuréticos de alça com tiazídicos (abaixando 0,4-0,8 mEq/L) ${ }^{18,19}$.

\section{$10^{\circ}$ Passo - SITUAÇÕES ESPECIAIS}

Apesar de não ser objetivo dessa atualização, conhecer algumas situações específicas da prática diária torna-se importante. Nelas, a ativação neuro-hormonal (SRAA e simpático) aumentará a reabsorção de sódio no túbulo proximal e no túbulo contorcido distal, reduzindo o impacto do bloqueio da bomba $\mathrm{Na} / \mathrm{K} / 2 \mathrm{Cl}$. Daí, com a progressão da doença e consequente impacto do eixo neuro-hormonal, haverá a necessidade de uma maior dose de furosemida para atingir a concentração intraluminal adequada (dose efetiva) e por consequência induzir natriurese. As mais comuns são:

\section{Ascite}

2. Glomerulopatias e Doença Renal Crônica (DRC)

3. Insuficiência Cardíaca Crônica (IC)

4. Hipovolemia

\section{ASCITE}

Comum à maior parte dos casos, temos a ativação neuro-hormonal, gerando um aumento da ativação do sistema renina-angiotensina aldosterona (SRAA), do hormônio antidiurético (ADH) e da atividade simpática que, em parte, justificam a exigência de uma maior dose de furosemida para atingir dose efetiva. 
No paciente com ascite, benigna ou maligna, haverá ativação neuro-hormonal pela redução do volume circulante efetivo, mas principalmente pelo aumento da congestão venosa renal, com este último assumindo um local de destaque ${ }^{20}$. Esse mecanismo multifatorial induzirá vasoconstricção intrarrenal e consequentemente uma exacerbada reabsorção de sódio e água - principalmente em um contexto de ausência de restrição de sódio.

Em consequência do exposto, além das alternativas à resistência destacadas em todo o texto, garantir a restrição de sódio e avaliar indicação de parancenteses programadas são estratégias cruciais no adequado manejo clínico desses pacientes.

\section{GLOMERULOPATIAS E INSUFICIÊNCIA RENAL CRÔNICA}

Nas glomerulopatias em geral, a lesão da barreira de filtração glomerular gera albuminúria, fazendo com que parte da furosemida chegue na alça de Henle ligada à albumina e comprometa a sua eficácia, afinal, apenas a porção livre da furosemida é ativa ${ }^{21}$. Além deste, foi descrito outro mecanismo pelo qual a plasmina luminal ativa o canal epitelial de sódio $(\mathrm{ENaC})$ no ducto coletor. A plasmina pode também ativar prostasina, que também pode clivar $\mathrm{ENaC}^{22-24}$. Estudos posteriores indicaram que este mecanismo poderia também desempenhar um papel na retenção de sódio associada à pré-eclâmpsia, hipertensão resistente, insuficiência cardíaca e nefropatia diabética $^{22}$. Além disso, $25 \%$ dos pacientes em síndrome nefrótica são hipovolêmicos (normalmente aqueles com hipoalbuminemia severa) e consequentemente com maior ativação do SRAA, ADH e sistema nervoso simpático, sendo por natureza pouco responsivos à ação do diurético, devido à reabsorção tubular compensatória e redução do fluxo sanguíneo real, e com ele, da oferta de furosemida ao túbulo.

$\mathrm{Na}$ disfunção renal crônica (DRC), apesar do aumento do tempo de meia-vida dos diuréticos (Tabela 1 e Figura 3), será necessária uma maior dose dos diuréticos de alça para atingir a dose efetiva. Pacientes com insuficiência cardíaca e disfunção renal crônica têm níveis elevados de ácido orgânico circulante, como a ureia, que inibe competitivamente o transportador aniônico orgânico e reduz secreção tubular de furosemida ${ }^{16}$. Quanto maior o grau de disfunção renal, maior será a resistência intrínseca ao diurético e maior deverá ser a dose ofertada. Ao atingir essa dose, mesmo em um rim com disfunção crônica, haverá natriurese máxima, semelhante a um rim com função normal (Figura 6).

\section{INSUFICIÊNCIA CARDÍACA}

A insuficiência cardíaca é uma doença crônica e progressiva e, em sua fase avançada, assumirá uma fisiopatologia mais complexa, compondo a síndrome cardiorrenal. Esta, por sua vez, unirá os três principais mecanismos fisiopatológicos de indução de resistência ao uso de diuréticos: redução do volume circulante efetivo, aumento da pressão intra-abdominal e principalmente a congestão venosa renal ${ }^{24}$.

Com progressão da doença e agregação de meios "naturais" de adaptação/resistência ao uso de diuréticos, o paciente exigirá aumento continuado da dose do diurético para controle dos sintomas. Ratifica-se com isso o conceito de que a dose do diurético possui uma correlação inversa com o prognóstico do mesmo do paciente com insuficiência cardíaca: quanto maior a dose, menor a sobrevida do paciente ${ }^{25,26}$.

Apesar do componente multifatorial, sabe-se hoje que a resistência ao diurético de alça na IC ocorre predominantemente por aumento da reabsorção no túbulo distal, com uma minoria dos pacientes assumindo resistência pelo aumento da absorção de sódio no túbulo contorcido proximal (TCP) 27 . Ou seja, ratifica o racional de uso de diuréticos tiazidícos em pacientes resistentes ao uso de diuréticos de alça, deixando para posterior associação com inibidores de anidrase carbônica.

Esse fato não se restringe apenas a um marcador de progressão de doença, sendo hoje discutido os malecíficios da terapia diurética, com comprovada ativação neuro-hormonal e consequente estímulo à fibrogênese ${ }^{28,29}$, tanto pelo racional da ativação do SRAA pela natriurese como pelo estímulo vascular direto ${ }^{30}$. Esse mecanismo parece ser desencadeado pela hipovolemia relativa, ocasionada nos períodos de ação. Ou seja, deve-se conhecer bem os efeitos positivos e negativos da diureticoterapia ${ }^{31}$.

\section{HIPOVOLEMIA}

Pacientes edemaciados possuem sobrecarga corporal de sódio, mas isso não é garantia de hipervolemia. Ao deparar-se com paciente refratário ao uso do diurético, avalie com maior cuidado a volemia do mesmo. Tanto a furosemida ${ }^{32}$ como a redução do volume circulante efetivo desencadearão aumento de hormônios regulatórios da volemia, como angiotensina II (AII) e aldosterona. Esses hormônios reduziriam vasoconstrição da vasculatura renal, (com consequente redução da velocidade da sua chegada ao seu sítio de ação); aumentam reabsorção de sódio no TCP; ativam receptores de sódio no túbulo distal, com consequente aumento de reabsorção de $\mathrm{Na}$ - tais como cotransporta- 
dor de $\mathrm{NaCl}$, canais de $\mathrm{Na}$ dependente do cotransporte $\mathrm{Cl} / \mathrm{HCO} 3$ e pendrinas ${ }^{33-36}$; e por fim a hipertrofia dos túbulos distais. Com isso, avaliação da volemia tornar-se-á um pilar fundamental na avaliação da resposta terapêutica e resistência aos diuréticos de alça.

Aplicação prática 9 - Atentar para estimativa de volemia, principalmente em pacientes normotensos, com múltiplos anti-hipertensivos, com perda ponderal nos dias anteriores, vasculopatas (doença cerebrovascular, doença arterial oclusiva periférica, diabéticos tipo II, etc). Imprescindível avaliação diária da diurese, peso diário em jejum e controle pressórico.

\section{EFEITOS COLATERAIS}

Muito temido e citado na prática diária, os riscos de surdez, zumbido ou perda da acuidade reversível parecem ser fatos históricos, estimados em um momento de comum associação ao aminoglicosídeo e com doses superiores a $240 \mathrm{mg}$ por hora ${ }^{37-39}$. No entanto, não vem sendo mostrado aumento da prevalência nas populações de risco, como em hipertensos ${ }^{40}$, sendo essa a impressão clínica: baixo risco de ototoxicidade irreversível, com episódios isolados e temporários de zumbido quando em alta dose.

Os distúrbios hidroeletrolíticos, estes sim, são muito comuns em pacientes com uso crônico de furosemida. Afinal, parte dos cátions são reabsorvidos através do transporte paracelular na porção espessa da alça de Henle (Figura 1). Destaque para hipernatremia, presente pela diurese hipotônica induzida pelo diurético de alça (mais água do que sódio), hipocalemia e alcalose metabólica.

Dados atuais sinalizam para outro impacto da hipocalemia induzida pelo diurético de alça: ativação de proteínas quinases que levam à fosforilação e ativação do cotransportador $\mathrm{Na} / \mathrm{Cl}$ do TCD (túbulo contorcido distal), alertanto para a necessidade de sua correção ${ }^{41}$.

\section{CONSIDERAÇÕES FINAIS}

Portanto, conhecer a farmacocinética e a farmacodinâmica da furosemida torna-se imprescindível para o uso dessa droga tão empregada, evitando subdoses, piora da qualidade de vida e maior custo em saúde.

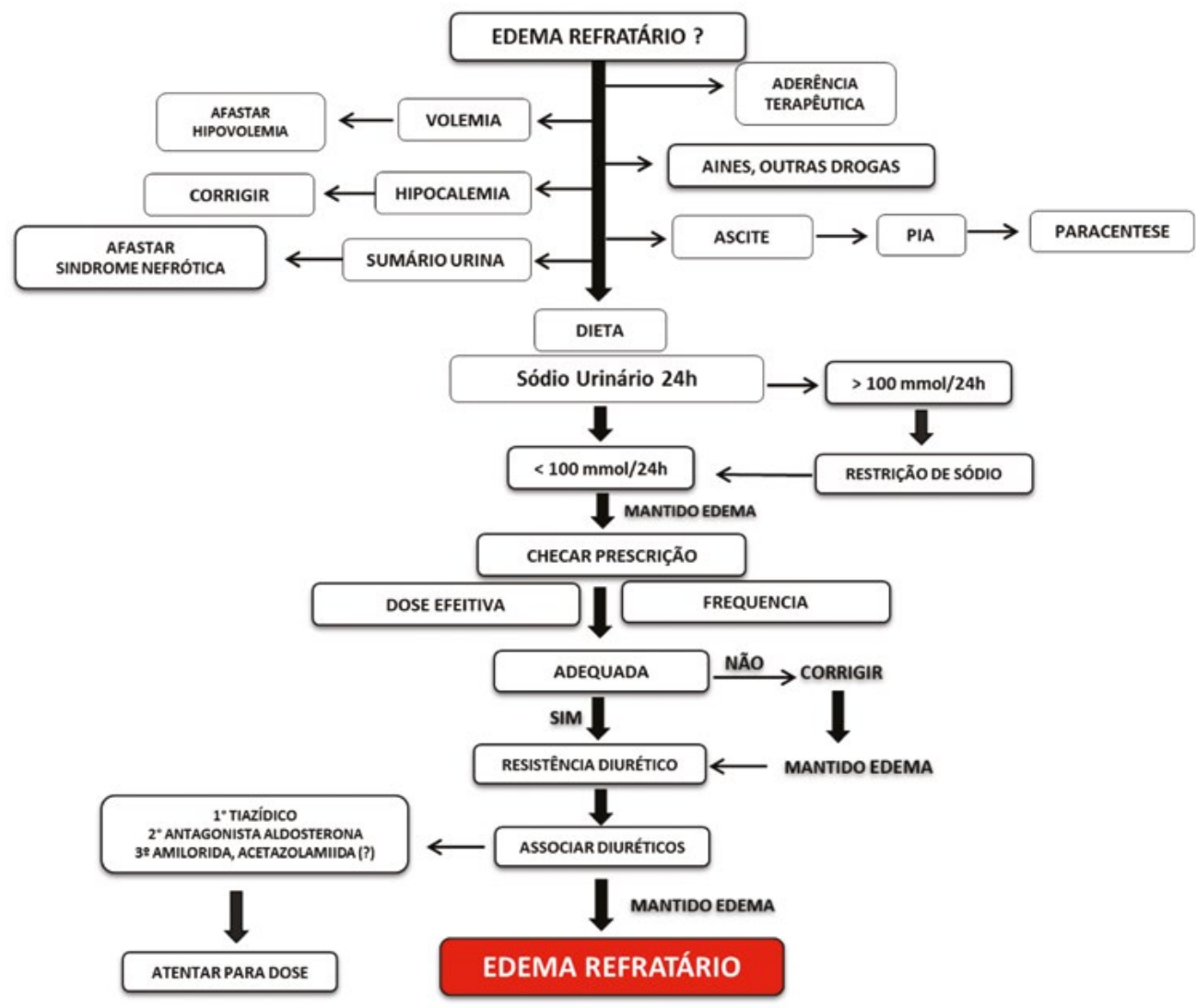

Figura 8 - PIA (pressão intra-abdominal). Adapted: Hoorn EJ, Ellison DH. Diuretic Resistance. Am J Kidney Dis Off J Natl Kidney Found. 2017 Jan;69(1):136-42. (42). 


\section{REFERÊNCIAS}

1. Isenring $P$, Forbush $B$ : Ion transport and ligand binding by the $\mathrm{Na}-\mathrm{K}-\mathrm{Cl}$ cotransporter, structure-function studies. Comp Biochem Physiol A Mol Integr Physiol 130:487-497, 2001.

2. Brater DC. Diuretic therapy. N Engl J Med 339: 387-395, 1998.

3. Vasko MR, Cartwright DB, Knochel JP, Nixon $\mathrm{JB}$, Brater DC. Furosemide absorption altered in decompensated congestive heart failure. Ann Intern Med. 1985;102:314-8.

4. Brater, D. Craig. "Resistance to loop diuretics. Why it happens and what to do about it." Drugs 30.5 (1985): 427-443. (3).

5. Sjöström PA, Odlind BG, Beermann BA, Hammarlund-Udenaes $M$. On the mechanism of acute tolerance to furosemide diuresis. Scand J Urol Nephrol. 1988;22(2):133-40.

6. Wilcox CS, Mitch WE, Kelly RA, Skorecki K, Meyer TW, Friedman PA, et al. Response of the kidney to furosemide. I. Effects of salt intake and renal compensation. J Lab Clin Med. 1983 Sep;102(3):450-8.

7. Ellison $\mathrm{DH}$. Diuretic therapy and resistance in congestive heart failure.Cardiology 2001;96:132- $43(4,5)$.

8. Pichette, V., Geadah, D. and du Souich, P. (1996), The influence of moderate hypoalbuminaemia on the renal metabolism and dynamics of furosemide in the rabbit. British Journal of Pharmacology, 119: 885-890.

9. Uwai $\mathrm{Y}$, Saito $\mathrm{H}$, Hashimoto $\mathrm{Y}$, et al: Interaction and transport of thiazide diuretics, loop diuretics, and acetazolamide via rat renal organic anion transporter rOAT1. J Pharmacol Exp Ther 295:261-265, 2000.

10. Brater DC, Voelker JR. Use of diuretics in patients with renal disease. In: Pharmacotherapy of Renal Disease and Hypertension (Contemporary Issues in Nephrology), Bennett WM, McCarron DA (Eds), Churchill Livingstone, New York 1987. Vol 17.

11. Wilcox CS, Mitch WE, Kelly RA, Skorecki K, Meyer TW, Friedman PA, et al. Response of the kidney to furosemide. I. Effects of salt intake and renal compensation. J Lab Clin Med. 1983 Sep;102(3):450-8.

12. Ferguson JA, Sundblad KJ, Becker PK, Gorski JC, Rudy DW, Brater DC. Role of duration of diuretic effect in preventing sodium retention. Clin Pharmacol Ther. 1997 Aug;62(2):203-8.

13. Ellison DH, Velázquez $\mathrm{H}$, Wright FS. Adaptation of the distal convoluted tubule of the rat. Structural and functional effects of dietary salt intake and chronic diuretic infusion. J Clin Invest. 1989 Jan;83(1):113-26.

14. Eshaghian S, Horwich TB, Fonarow GC. Relation of loop diuretic dose to mortality in advanced heart failure. Am J Cardiol. 2006 Jun 15;97(12):1759-64.

15. Hasselblad V, Gattis Stough W, Shah MR, Lokhnygina Y, O'Connor CM, Califf RM, et al. Relation between dose of loop diuretics and outcomes in a heart failure population: results of the ESCAPE trial. Eur $\mathrm{J}$ Heart Fail. 2007 Oct;9(10):1064-9.

16. Ter Maaten JM, Valente MAE, Damman K, Hillege $H L$, Navis G, Voors AA. Diuretic response in acute heart failure-pathophysiology, evaluation, and therapy. Nat Rev Cardiol. 2015 Mar;12(3):184-92.

17. Ellison $\mathrm{DH}$. The physiologic basis of diuretic synergism: its role in treating diuretic resistance. Ann Intern Med. 1991 May 15;114(10):886-94.

18. Jentzer JC, DeWald TA, Hernandez AF. Combination of loop diuretics with thiazide-type diuretics in heart failure. J Am Coll Cardiol. 2010 Nov 2;56(19):1527-34.

19. Hunt SA, Abraham WT, Chin MH, Feldman AM, Francis GS, Ganiats TG, et al. 2009 Focused update incorporated into the ACC/AHA 2005 Guidelines for the Diagnosis and Management of Heart Failure in Adults A Report of the American College of Cardiology Foundation/American Heart Association Task Force on Practice Guidelines Developed in Collaboration With the International Society for Heart and Lung Transplantation. J Am Coll Cardiol. 2009 Apr 14;53(15): e1-90.

20. Chang Y, Qi X, Li Z, Wang F, Wang S, Zhang Z, et al. Hepatorenal syndrome: insights into the mechanisms of intra-abdominal hypertension. Int $\mathrm{J}$ Clin Exp Pathol. 2013;6(11):2523-8.

21. Pichette V, Geadah D, du Souich P. The influence of moderate hypoalbuminaemia on the renal metabolism and dynamics of furosemide in the rabbit. Br J Pharmacol. 1996 Nov;119(5):885-90.

22. Hoorn EJ, Ellison DH. Diuretic Resistance. Am J Kidney Dis Off J Natl Kidney Found. 2017 Jan;69(1):136-42.

23. Svenningsen $P$, Uhrenholt TR, Palarasah $Y$, Skjødt K, Jensen BL, Skøtt O. Prostasin-dependent activation of epithelial $\mathrm{Na}+$ channels by low plasmin concentrations. Am J Physiol Regul Integr Comp Physiol. 2009 Dec;297(6):R1733-1741.

24. Verbrugge FH, Dupont M, Steels $P$, Grieten L, Malbrain M, Tang WHW, et al. Abdominal contributions to cardiorenal dysfunction in congestive heart failure. $J$ Am Coll Cardiol. 2013 Aug 6;62(6):485-95 .

25. Eshaghian S, Horwich TB, Fonarow GC. Relation of loop diuretic dose to mortality in advanced heart failure. Am J Cardiol. 2006 Jun 15;97(12):1759-64.

26. Hasselblad V, Gattis Stough W, Shah MR, Lokhnygina Y, O'Connor CM, Califf RM, et al. Relation 
between dose of loop diuretics and outcomes in a heart failure population: results of the ESCAPE trial. Eur $\mathrm{J}$ Heart Fail. 2007 Oct;9(10):1064-9.

27. Rao VS, Planavsky N, Hanberg JS, Ahmad T, Brisco-Bacik MA, Wilson FP, Jacoby D, Chen M, Tang WHW, Cherney DZI, Ellison DH, Testani JM: Compensatory distal reabsorption drives diuretic resistance in human heart failure [published online ahead of print July 24, 2017]. J Am Soc Nephrol.

28. Francis GS, Siegel RM, Goldsmith SR, Olivari MT, Levine TB, Cohn JN. Acute vasoconstrictor response to intravenous furosemide in patients with chronic congestive heart failure. Activation of the neurohumoral axis. Ann Intern Med. 1985 Jul;103(1):1-6.

29. Chen HH, Redfield MM, Nordstrom LJ, Cataliotti A, Burnett JC. Angiotensin II AT1 receptor antagonism prevents detrimental renal actions of acute diuretic therapy in human heart failure. Am J Physiol Renal Physiol. 2003 May;284(5):F1115-1119.

30. Dormans TP, Pickkers P, Russel FG, Smits P. Vascular effects of loop diuretics. Cardiovasc Res. 1996 Dec;32(6):988-97.

31. Felker GM, Mentz RJ. Diuretics and ultrafiltration in acute decompensated heart failure. J Am Coll Cardiol. 2012 Jun 12;59(24):2145-53.

32. Gary S. Francis, M.D.; Robert M. Siegel, M.D.; Steven R. Goldshmith, M.D.; Maria Teresa Olivari, M.D.; T. Barry Levine, M.D.; Jay N. Cohn, M.D. Acute Vasoconstrictor Response to Intravenous Furosemide in Patients with Chronic Congestive Heart Failure: Activation of the Neurohumoral Axis. Ann Intern Med. 1985;103(1):1-6.

33. Van Der Lubbe N, LimCH, Fenton RA, Meima ME, Jan Danser AH, Zietse R, Hoorn EJ: Angiotensin II induces phosphorylation of the thiazide-sensitive sodium chloride cotransporter independent of aldosterone. Kidney Int 79: 66-76, 2011.

34. Verlander JW, Hassell KA, Royaux IE, Glapion DM, Wang ME, Everett LA, Green ED, Wall SM: Deoxycorticosterone upregulates PDS (Slc26a4) in mouse kidney: Role of pendrin in mineralocorticoidinduced hypertension. Hypertension 42: 356-362, 2003.

35. Pácha J, Frindt G, Antonian L, Silver RB, Palmer LG: Regulation of $\mathrm{Na}$ channels of the rat cortical collecting tubule by aldosterone. J Gen Physiol 102: 25-42, 1993 10. Zaika O, Mamenko M, Staruschenko A, Pochynyuk O: Direct activation of ENaC by angiotensin II: Recent advances and new insights. Curr Hypertens Rep 15: 17-24, 2013.

36. Hadchouel J, Büsst C, Procino G, Valenti G, Chambrey R, Eladari D: Regulation of extracellular fluid volume and blood pressure by pendrin. Cell Physiol Biochem 28: 505-512, 2011.

37. Sheffield PA, Turner JS. Ototoxic drugs: a review of clinical aspects, histopathologic changes and mechanisms of action. South Med J 1971;64:359-63.

38. Cooperman LB, Rubin IL. Toxicity of ethacrynic acid and furosemide. Am Heart J 1973;85:831-4.

39. Arnold W, Nadol JB Jr, Weidauer H. Ultrastructural histopathology in a case of human ototoxicity due to loop diuretics. Acta Otolaryngol. 1981 May-Jun;91(5-6):399-414.

40. Lin BM, Curhan SG, Wang M, Eavey R, Stankovic KM, Curhan GC.Hypertension, Diuretic Use, and Risk of Hearing Loss. Am J Med. 2016 Apr; 129 (4): 416-22.

41. Terker AS, Zhang C, McCormick JA, Lazelle RA, Zhang C,Meermeier NP, Siler DA, Park HJ, Fu Y, Cohen DM, Weinstein AM, Wang WH, Yang CL, Ellison $\mathrm{DH}$ : Potassium modulates electrolyte balance and blood pressure through effects on distal cell voltage and chloride. Cell Metab 21: 39-50, 2015.

42. Hoorn EJ, Ellison DH. Diuretic Resistance. Am J Kidney Dis Off J Natl Kidney Found. 2017 Jan;69(1):136-42.

\section{1- Serviço de Nefrologia do HSI}

Endereço para correspondência: drcesarfilho@hotmail.com 